\title{
Modeling and Analysis of Electromagnetic Field and Temperature Field of Permanent-Magnet Synchronous Motor for Automobiles
}

\author{
Meixia Jia ${ }^{1,2}$, Jianjun $\mathrm{Hu}^{1,2, *(\mathbb{D}}$, Feng Xiao ${ }^{1,2}{ }^{\mathbb{D}}$, Ying Yang ${ }^{1,2}$ and Chenghao Deng ${ }^{3}$ \\ 1 State Key Laboratory of Mechanical Transmissions, School of Automotive Engineering, \\ Chongqing University, Chongqing 400044, China; jiameixia23@163.com (M.J.); 15079140747@163.com (F.X.); \\ yangying2020cqu@163.com (Y.Y.) \\ 2 College of Automotive Engineering, Chongqing University, Chongqing 400044, China \\ 3 Chongqing Chang'an New Energy Automobile Technology Co., Ltd., Chongqing 400023, China; \\ dengch@changan.com.cn \\ * Correspondence: hujianjun@cqu.edu.cn
}

Citation: Jia, M.; Hu, J.; Xiao, F.; Yang, Y.; Deng, C. Modeling and Analysis of Electromagnetic Field and Temperature Field of PermanentMagnet Synchronous Motor for Automobiles. Electronics 2021, 10, 2173. https://doi.org/10.3390/ electronics10172173

Academic Editor: Rui Esteves Araújo

Received: 16 August 2021

Accepted: 2 September 2021

Published: 6 September 2021

Publisher's Note: MDPI stays neutral with regard to jurisdictional claims in published maps and institutional affiliations.

Copyright: (c) 2021 by the authors. Licensee MDPI, Basel, Switzerland. This article is an open access article distributed under the terms and conditions of the Creative Commons Attribution (CC BY) license (https:/ / creativecommons.org/licenses/by/ $4.0 /)$.

\begin{abstract}
In order to study the interaction of electromagnetic fields and temperature fields in a motor, the iron loss curve at different frequencies of silicon steel and the B-H curve at different temperatures of the permanent magnet (PM) were obtained to establish the electromagnetic model of the permanent magnet synchronous motor (PMSM). Then, unidirectional and bidirectional coupling models were established and analyzed based on the multi-physical field. By establishing a bidirectional coupling model, the temperature field distribution and electromagnetic characteristics of the motor were analyzed. The interaction between temperature and electromagnetic field was studied. Finally, the temperature of the PMSM was tested. The results showed that the bidirectional coupling results were closer to the test result because of the consideration of the interaction between electromagnetic and thermal fields.
\end{abstract}

Keywords: permanent-magnet synchronous motor; electromagnetic loss; temperature field; electromagnetic field; coupling

\section{Introduction}

\subsection{Motivation}

With the development of new energy vehicles, the permanent-magnet synchronous motor (PMSM) has been widely used as the main power component. The PMSM itself is a strong nonlinear system with mechanical-electromagnetic-thermal multi-field coupling. Its performance and efficiency directly affect the power performance and economy of electric vehicles [1,2].

\subsection{Literature Review}

Many papers have been published on the detailed analysis of thermal fields. The temperatures of motors were analyzed to compare the temperature rise of the IPM and SPM [3], to take the transient loss power as the heat source [4], to improve the structure of the motor according to the temperature distribution [5], or to obtain the loss of the motor [6] by using the lumped parameter (LP) method. These works analyzed the motor temperature field using the LP method but did not involve the interaction between the electromagnetic field and temperature field. The influence of the stator core temperature on rotor thermal performance [7], the influence of the structure on the motor temperature field [8], and the influence of the inverter switching frequency and the air gap length on the loss [9] were analyzed by using a coupling model of fluid-temperature. These works mainly analyzed the flow field and temperature field of the motor that can provide a reference for motor cooling, but they still ignored the interaction of the temperature field and electromagnetic field. 
The thermal transient behavior of an air-cooled interior permanent-magnet synchronous motor (IPMSM) for the agricultural electric vehicle (AEV) was analyzed using the finite element method (FEM). The temperature changes of insulation and a permanent magnet under rated conditions were studied, but many assumptions were used in the modeling process [10]. The temperature distribution of the proposed high-speed PMSM was analyzed by using a fluid-thermal unidirectional model with the calculated power loss [11]. The model is a unidirectional model to study the effect of electromagnetic loss on temperature. The influence of an electromagnetic heat-absorbing structure on thermal performance was analyzed by using the lumped parameter thermal network method instead of the finite element method [12]. The temperature distribution of a permanent-magnet linear motor was analyzed by using the FEM and heat grid model under continuous working conditions to study the influence of the temperature rise on the motor thrust force and efficiency, but the influence of the electromagnetic field on the temperature field was ignored [13]. An inverse approach based on the machine's measured temperatures and its lumped thermal network was used to estimate the actual loss components in the motor [14]. However, the iron loss analyzed by the model was quite different from the test results. A method was presented to derive distributed multipole (DMP) models for characterizing the magnetic field and torque of permanent magnet (PM)-based devices [15]. The research only focused on the electromagnetic field and assumed that the temperature remains unchanged during operation. A novel hybrid drive multi-degree-of-freedom permanent-magnet motor was simulated to analyze the electromagnetic field, but the thermal field was ignored [16]. The air-gap magnetic field of an air-core monopole linear motor (AMLM) was established by using a surface magnetic charge model and an image method to reduce the calculation time [17]. The multi-physical field model was used to analyze the temperature field. However, the interaction between the electromagnetic field and temperature field was not analyzed. The power loss under the rated load was analyzed to compare the temperature distribution of four cooling schemes [18] using the electromagnetic thermal unilateral iteration method without considering the reverse effect of temperature on electromagnetism. Using the LP thermal network method, the calculated carrier harmonic loss and eddy current loss were used as the input of the temperature field to analyze the temperature of the motor [19]. It was regarded as a sequential coupling calculation method and could only analyze the effect of electromagnetic loss on the temperature field. The loss of the rated working condition was calculated by 2-D FEM [20]. The thermal circuit diagram of the permanent magnet synchronous motor is established, and the thermal field of the motor is obtained with the thermal resistance as the intermediate parameter [21]. The heat was calculated and applied to the temperature field instead of an automatic iterative process. This made the calculation process complex, similar to [22]. The coupling simulation calculation of electromagnetic heat, fluid dynamics analysis, and structural mechanics of the motor were realized with multi-physics finiteelement simulation software [23]. The temperature and displacement distribution were the main work, but the reaction of temperature to electromagnetism was ignored, which may lead to higher temperatures. A novel model predictive torque control of the interior permanent-magnet synchronous motor was put forward, but the influence of temperature change on the control parameters was not considered [24]. The torque ripple of the motor was analyzed through modeling [25], without considering the interaction of the electromagnetic thermal field. The rotor strength and permanent magnet temperature rise were considered to avoid the cumbersome iterative process in the design of a high-speed motor [26]. However, the interaction between the electromagnetic field and temperature field was not studied. Different temperature field models were established to simulate the temperature field distribution of the motor $[27,28]$. Both models were LP models, which mostly ignore the changes in motor parameters due to the changes in temperature or electromagnetic parameters in the actual process.

From the above analysis, it can be seen that scholars all over the world have conducted in-depth research on the temperature and electromagnetic performance, but little atten- 
tion has been paid to the interaction of coupling between the electromagnetic field and temperature field of a PMSM. A few studies on the coupling of the temperature field and electromagnetic field have only paid attention to the influence of the electromagnetic field on the temperature field. There are few in-depth studies on the reaction of the temperature field to the electromagnetic field. This is very disadvantageous to predict the performance change caused by temperature change in the actual operation of a motor. It is not conducive to the development of high-performance motors and its control strategy.

\subsection{Original Contributions of This Paper}

The PMSM itself is a strong nonlinear system with mechanical-electromagneticthermal multi-field coupling. The electromagnetic loss in the working process is the main reason for the temperature rise of the motor. High temperature not only increases the winding resistance and copper loss, but also affects other electromagnetic parameters. Too high a temperature may cause winding insulation layer failure and the PM to become permanently demagnetized. In order to study the interaction between the electromagnetic field and temperature field, a bidirectional coupling model was established in this paper. This model is closer to the actual work of the motor than the previous unidirectional coupling model [23]. The electromagnetic loss and temperature distribution of the motor were analyzed in detail. The interaction between the electromagnetic field and temperature field in the working process of the motor was further analyzed with the bidirectional coupling model. It can provide a reference for motor electromagnetic performance design, cooling system design, and accurate control of the motor.

\section{Motor Structure}

The analyzed motor is mainly divided into 12 parts. The specific structure and relative position relationship are shown in Figure 1. The coolant flow area, called the water jacket, includes the combined inlet pipe, outlet pipe, and jacket, which are regarded as a whole, called a water jacket. The other parts are the shell, stator, insulation filler glue, winding, rotor_mass, epoxy, rotor shaft, and magnet. Glue and epoxy are the substances that are filled around the windings and permanent magnets, respectively. The rotor_mass is the connecting part between the rotor and shaft. The air_gap region inside the motor is divided into two parts in the FEM models. One is the stationary region that remains still with the stator, called air_s. The other is a region of rotating air that rotates with the rotor, called air_r.

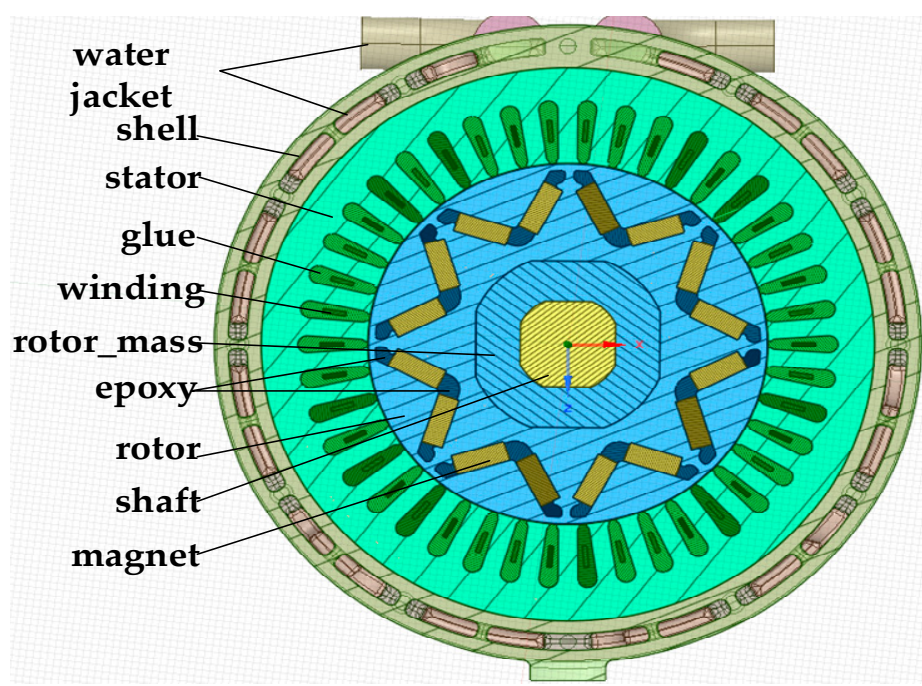

(a)

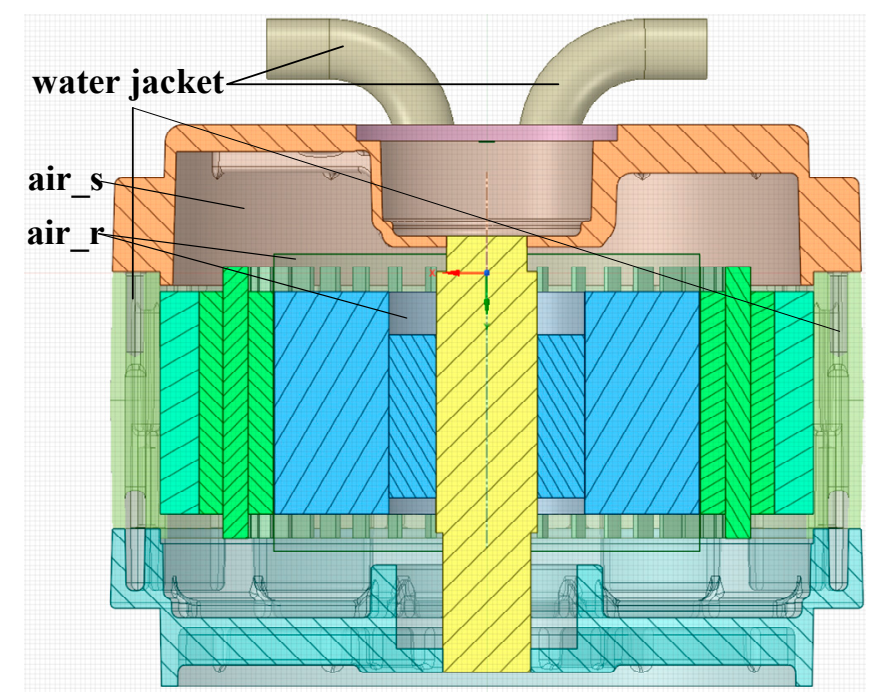

(b)

Figure 1. Structure of the PMSM. (a) Cross-section; (b) longitudinal section. 
The motor parameters are listed in the Table 1:

Table 1. Motor parameters.

\begin{tabular}{llll}
\hline Parameter & Value & Parameter & Value \\
\hline Current excitation & Sinusoidal & Phase number & 3 \\
Lamination factor & 0.95 & Pole pairs & 4 \\
Maximum current $(\mathrm{A})$ & 350 & Silicon steel & B35AV1900 \\
Rated Speed (rpm) & 1000 & Cooling method & Water-cooled \\
Rated Torque (Nm) & 100 & Magnet & N35UH_100 \\
\hline
\end{tabular}

\section{Loss Calculation}

\subsection{Iron Loss Calculation}

The main loss of the PMSM includes iron loss and copper loss during the operation. The iron loss can be divided into hysteresis loss, eddy current loss, and excess loss according to the Berttoti model [29]. Hysteresis loss is static loss. According to the Steinmetz Formula, the hysteresis loss $P_{h}$ consists of alternating hysteresis loss $P_{a h}$ and rotational hysteresis loss $P_{r h}$. It can be calculated as follows:

$$
P_{h}=P_{a h}+P_{r h}=K_{h} f B_{m}^{h}
$$

where $f$ and $B_{m}$ are the frequency and the magnitude of magnetic flux density, respectively. $K_{h}$ and $h$ are the coefficients of the hysteresis loss. Generally, when $B_{m}<1 \mathrm{~T}, h=1.6$; and when $B_{m}>1 \mathrm{~T}, h=1.5 \sim 2.5$.

Eddy current loss is macroscopic dynamic loss. Under the combined action of rotating magnetic and alternating magnetic fields, the eddy current loss $P_{e}$ can be calculated as follows:

$$
P_{e}=P_{a e}(t)+P_{r e}(t)=K_{a e}\left(f B_{m}\right)^{1.5}+K_{r e}\left(f B_{m}\right)^{1.5}=K_{e}\left(f B_{m}\right)^{1.5},
$$

where $K_{a e}$ and $K_{r e}$ are the coefficients of the eddy loss in an alternating magnetic field and rotating magnetic field, respectively. $K_{e}$ is the coefficient of the total eddy loss that depends on the type of silicon steel and its lamination thickness.

Excess loss is microscopic dynamic loss caused by domain wall bending. Under the combined action of rotating magnetic and alternating magnetic fields, the excess current loss $P_{a}$ is:

$$
P_{a}=P_{a a}(t)+P_{r a}(t)=K_{a a}\left(f B_{m}\right)^{1.5}+K_{r a}\left(f B_{m}\right)^{1.5}=K_{a}\left(f B_{m}\right)^{1.5},
$$

where $K_{a a}$ and $K_{r a}$ are the coefficients of excess loss in an alternating magnetic field and rotating magnetic field, respectively. $K_{a}$ is the coefficient of the total excess loss.

The iron loss is not only related to the silicon steel used by the motor, but also varies with the frequency, working temperature, and load of the motor. For the latter one, this can be stated with Equation (4).

$$
T_{e m}=\frac{\sqrt{2}}{4} \cdot \pi \cdot B_{m} \cdot L_{e f} \cdot D_{i 1}{ }^{2} \cdot A_{1} \cdot 10^{-4},
$$

where $T_{e m}$ is the electromagnetic torque, $L_{e f}$ is the axial length of motor, $D_{i 1}$ is the inner diameter of the stator, and $A_{1}$ is the linear current density. According to Equation (4), the change in $B_{m}$ can also reflect the change in load. The impact of the load is not considered in this manuscript but will be considered in future work.

The core loss under sinusoidal AC excitation is measured by the AC power meter method. The AC power meter adopts the double winding connection method, and the iron loss can be directly measured by a power analyzer. The relationship between iron loss power $\mathrm{P}$ and flux density B at different frequencies of the silicon steel is shown in Figure 2. 


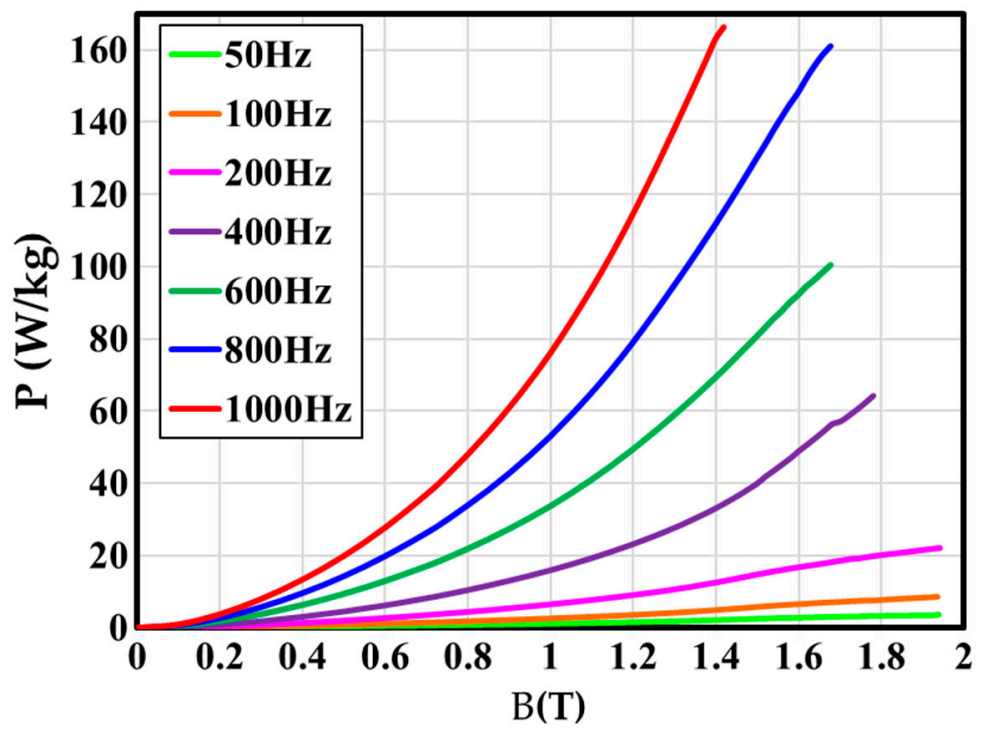

Figure 2. Iron loss with the magnetic flux density at different frequencies.

Figure 2 shows that, for the same frequency, as the magnetic flux density (B) increases, so does the core loss, which is consistent with the principle of the core loss. With the same flux density, the iron loss of the motor increases with the frequency, and the higher the frequency, the higher the increase rate of iron loss. That is, with the increase in motor speed, the iron loss of the motor will also increase substantially. After fitting the loss power curves at different frequencies, the loss coefficients of the silicon steel used in the motor are calculated as follows: $K_{h}=67.508 \mathrm{~W} \cdot \mathrm{s} /\left(\mathrm{m}^{3} \cdot \mathrm{T}^{\mathrm{h}}\right), K_{e}=0.465791 \mathrm{~W} \cdot \mathrm{s}^{1.5} /\left(\mathrm{m}^{3} \cdot \mathrm{T}^{1.5}\right)$, $K_{a}=0.000306 \mathrm{~W} \cdot \mathrm{s}^{1.5} /\left(\mathrm{m}^{3} \cdot \mathrm{T}^{1.5}\right), h=1.7509$.

Temperature changes during motor operation will also affect the working characteristics of the PM. The demagnetization law of the PM was tested by a dynamic hysteresis loop tester. The hysteresis loop can be observed and recorded directly by an oscilloscope [30]. As the motor temperature changes, the magnetic change law of the demagnetization curve of the PM used in the motor is shown in Figure 3.

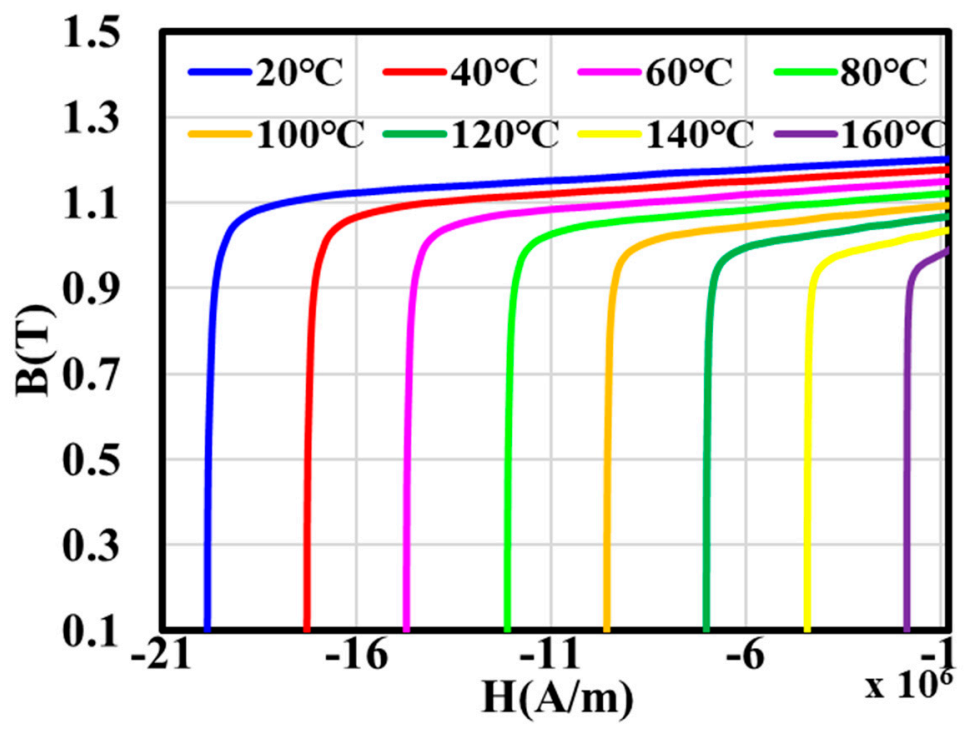

Figure 3. Demagnetization B-H curve at different temperatures.

In Figure 3, with the increase in temperature, the density of remanent magnetism $B_{r}$ and the coercive force $H_{c}$ of the permanent magnet decrease. The decrease in $B_{r}$ reduces the 
maximum power capacity of the motor. The decrease in coercivity will affect the stability of the permanent magnet and increase the irreversible loss of magnetic induction. The relative permeability can be calculated with Equation (5).

$$
\mu_{r}=\frac{B}{\mu_{0} H^{\prime}}
$$

where $\mu_{r}$ is the relative permeability and $\mu_{0}$ is the permeability of vacuum. $B$ and $H$ are the magnetic flux density and magnetic field strength, respectively.

Based on the above B-H curves at different temperatures, the curves of the relative permeability and coercive force of magnets changing with temperature can be obtained. The relative permeability and coercive force both at $20^{\circ}$ are assumed to be 1 , and as the basis. The ratio of the relative permeability and the coercive force at different temperatures to the relative permeability and the coercive force both at $20^{\circ}$ vary with temperature, as shown in Figure 4, respectively.

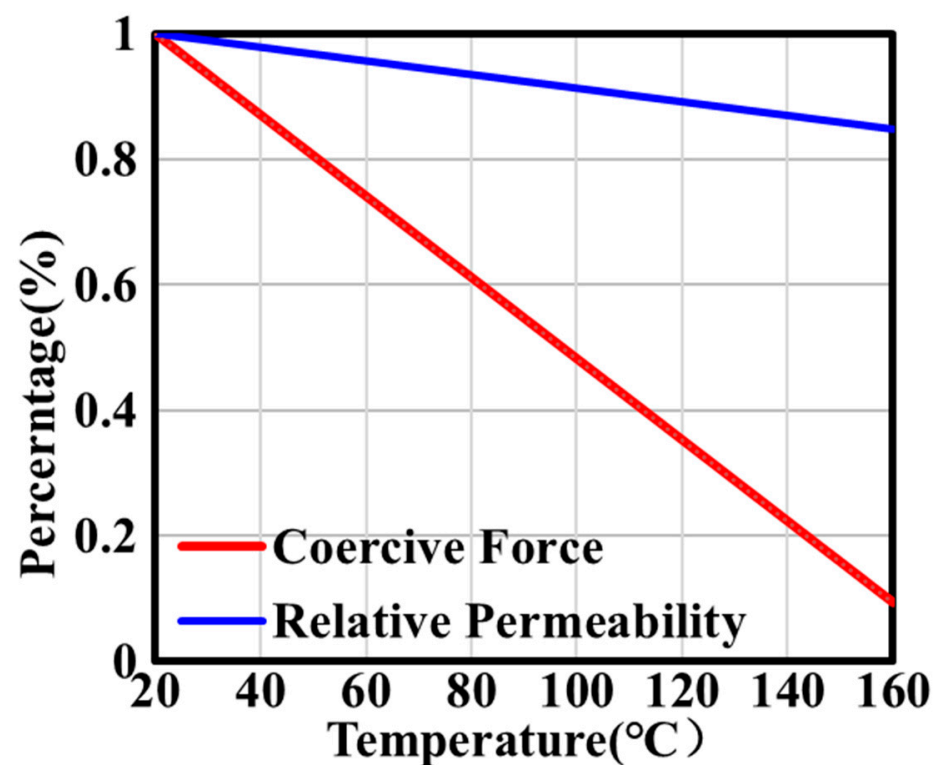

Figure 4. PM relative permeability and coercive force.

\subsection{Copper Loss Calculation}

The resistance of the copper can be calculated with Equation (6).

$$
R=\frac{R_{0}(235+T)}{235+T_{0}},
$$

where $R_{0}$ is the resistance at indoor temperature $T_{0} . T$ is the actual operating temperature of the motor.

The relative permeability and bulk conductivity both at $20^{\circ}$ are assumed to be 1 , and as the basis. The ratio of the relative permeability and the bulk conductivity at different temperatures to the relative permeability and the bulk conductivity both at $20^{\circ}$ vary with temperature, as shown in Figure 5, respectively. 


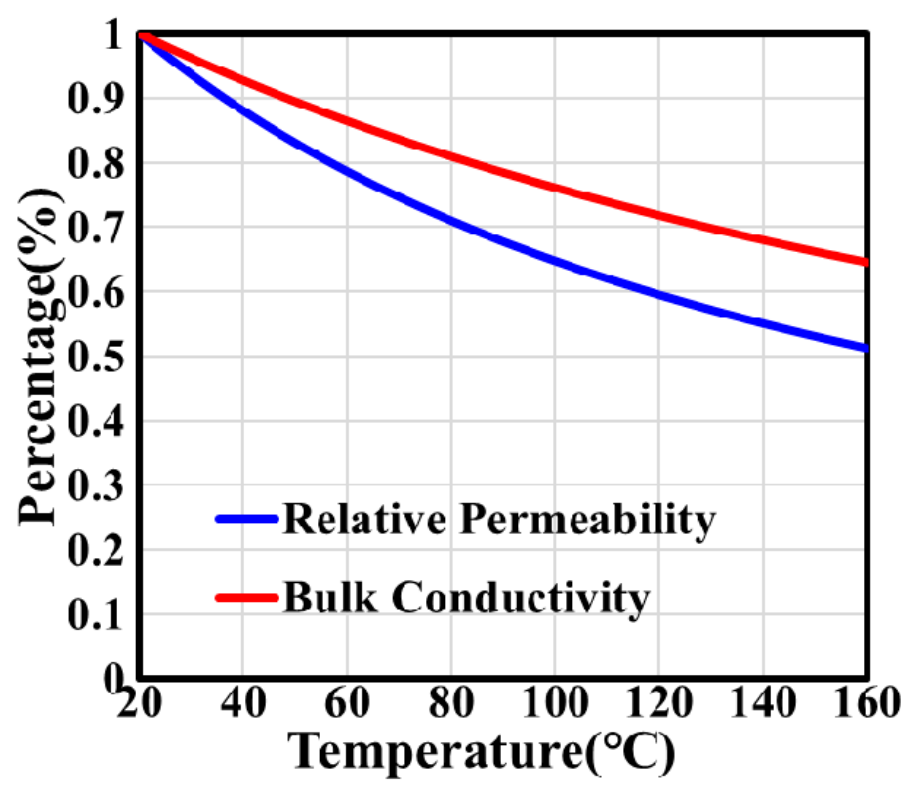

Figure 5. Winding relative permeability and bulk conductivity with temperature.

In a motor, the ac copper loss $P_{c u}$ with the skin and proximity effects can be expressed as Equation (7) [18]:

$$
P_{c u}=k_{a c} P_{d c}
$$

The $k_{a c}$ is related to the ratio of wire thickness to skin depth $(\delta)$ for different frequencies. The skin depth can be calculated as Equation (8). The coefficient $k_{a c}$ can be calculated as Equation (9) [31].

$$
\begin{gathered}
\delta=\sqrt{\frac{\rho_{c}}{\pi f \mu_{0} \mu_{r}}}, \\
k_{a c}=\frac{W}{\delta},
\end{gathered}
$$

where $\rho_{c}$ is the electrical resistivity of the conductor, $\mu_{r}$ is the relative permeability, $f$ is the frequency, $\mu_{0}$ is the permeability of the free space $\left(4 \pi \times 10^{-7} \mathrm{H} / \mathrm{m}\right)$, and $W$ is the effective area of the winding.

$P_{d c}$ is the copper loss of the motor in direct current. It can be calculated as Equation (10).

$$
P_{d c}=m I^{2} R,
$$

where $m$ is phase number, $I$ is the winding current, and $R$ is the winding resistance in actual work.

In Figure 4, with the increase in temperature, the relative permeability and the coercivity of the permanent magnet gradually decrease. The parameters are calculated as follows [32]:

$$
\begin{aligned}
\alpha_{B r} & =\frac{B_{1}-B_{0}}{B_{o}\left(t_{1}-t_{0}\right)} \\
\alpha_{H c} & =\frac{H_{c 1}-H_{c 0}}{H_{c 0}\left(t_{1}-t_{0}\right)}
\end{aligned}
$$

where $\alpha_{B r}$ is the temperature coefficient of the magnetic flux density and $\alpha_{H c}$ is the temperature coefficient of coercivity force. $B_{1}$ and $B_{0}$ are the magnetic flux density at temperatures $t_{1}$ and $t_{0}$, respectively. $H_{c 1}$ and $H_{c 0}$ are the coercivity force at temperatures $t_{1}$ and $t_{0}$, respectively. According to Figure 3, the remanence density and coercivity of the permanent magnet can be obtained at different temperatures. The temperature $t_{0}$ is the reference temperature, which is $20^{\circ}$. The temperature coefficients of the relative permeability and the coercive force can be calculated as: $\alpha_{B r}=0.0011, \alpha_{H c}=0.0065$. 
In Figure 5, with the increase in temperature, the relative permeability of the windings decreases continuously. As the resistance value is the reciprocal of the conductance, as the temperature increases, the resistance value of the winding increases. Therefore, according to Equation (5), the motor copper loss increases with the temperature.

\subsection{Model Setup}

Power loss in the operation process of the motor will eventually be converted into heat energy. In the steady state, heat production and heat loss reach an equilibrium so that the temperature remains constant. For the transient period, the equation is as follows:

$$
O d t=c M d(\Delta \theta)+\alpha A(\Delta \theta) d t,
$$

where $O$ is the total loss of the motor, $c$ is the specific heat capacity, $M$ is the mass, $\Delta \theta$ is the temperature rise of the object, $A$ is the surface heat dissipation area, $t$ is the time, and $\alpha$ is the surface heat dissipation coefficient. The motor is water-cooled. In the process of motor operation, in addition to heat conduction and heat radiation, there is heat convection between the casing and the cooling water jacket. Heat propagation between solids and liquids is calculated as follows:

$$
\begin{aligned}
& q_{s}=\frac{k_{s}}{\Delta n}\left(T_{w}-T_{s}\right)+q_{r a d}, \\
& q_{L}=h_{f}\left(T_{w}-T_{f}\right)+q_{r a d},
\end{aligned}
$$

where $h_{f}$ is the fluid-side local heat transfer coefficient and $T_{w}$ is the wall surface temperature. $T_{s}$ and $T_{f}$ are the local solid and fluid temperature, respectively. $q_{r a d}$ is the radiative heat flux. $k_{s}$ is the thermal conductivity of the solid. $\Delta n$ is the distance between the wall surface and the solid cell center.

The electromagnetic model was established according to the measured parameters of the silicon steel sheet and permanent magnet in Ansys Electronics software. The thermal model was established in Fluent software. The motor model is shown in Figure 6.

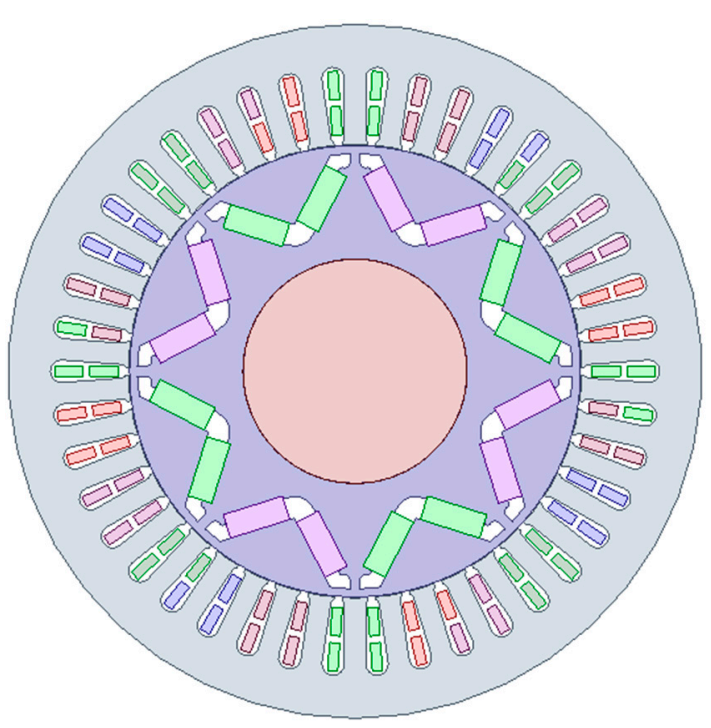

(a)

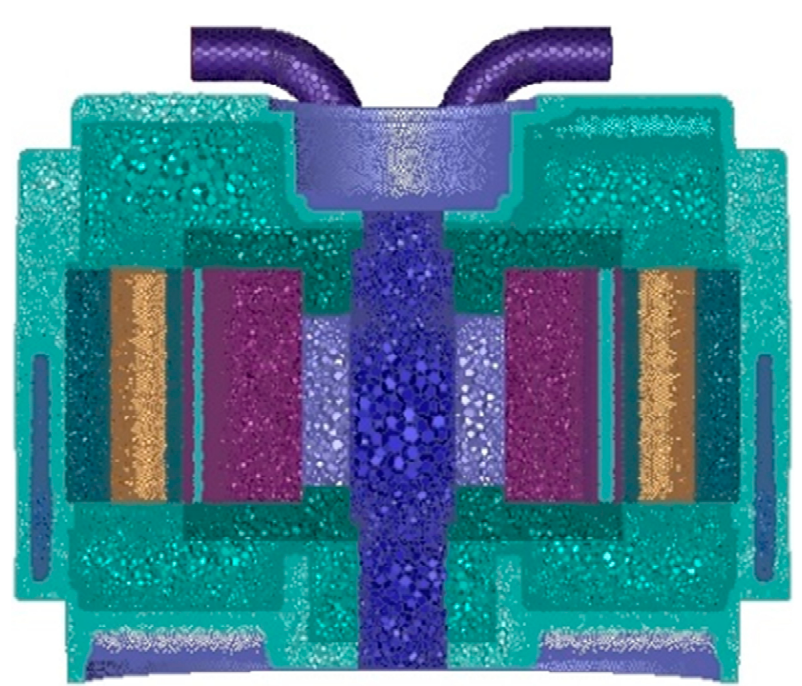

(b)

Figure 6. Motor model. (a) Electromagnetic model; (b) cross-sectional mesh. 


\section{Thermal Field Analysis}

\subsection{Effect of Electromagnetic Field on Temperature Distribution}

Two models of the PMSM of the unidirectional coupling model and bidirectional coupling model were established successively in this paper. In both models, the electromagnetic loss is used as the heat source of the temperature field. In unidirectional coupling analysis, in addition to the winding volume heat production rate, the core loss calculated by the electromagnetic model is mapped to the temperature field model in the form of a heat source. In bidirectional coupling analysis, the iron loss power is transferred to the thermal model as heat. After the calculation is finished in the thermal field, the temperature data are fed back to the electromagnetic model. The electromagnetic model calculates the loss of the motor according to the new temperature to complete a bidirectional iteration of temperature data and electromagnetic data.

The parameters of the thermal model are listed in Table 2.

Table 2. Parameters of the thermal model.

\begin{tabular}{llll}
\hline Parameters & Value & Parameters & Value \\
\hline Rotor speed $(\mathrm{rpm})$ & 1000 & Outlet pressure $(\mathrm{Pa})$ & 0 \\
Inlet velocity $(\mathrm{m} / \mathrm{s})$ & 0.453 & Volumetric heat generation & $1,244,805$ \\
Inlet temperature $(\mathrm{K})$ & 319 & rate $\left(\mathrm{w} / \mathrm{m}^{3}\right)$ & 5 \\
\hline
\end{tabular}

The temperature distributions of the winding, stator, and shell with the unidirectional and bidirectional coupling model are shown in Figures 7-9, respectively.

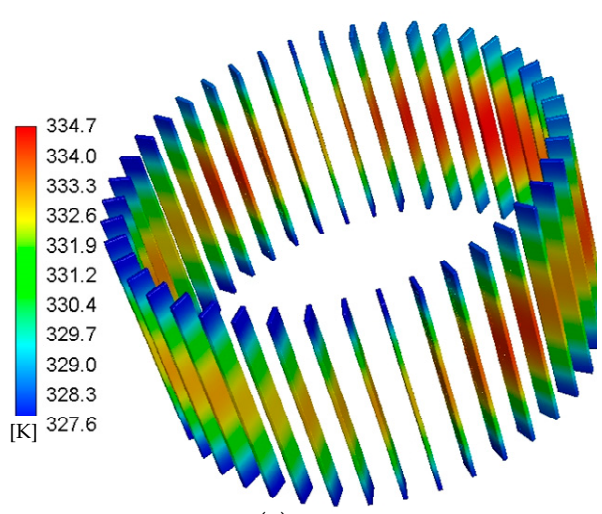

(a)

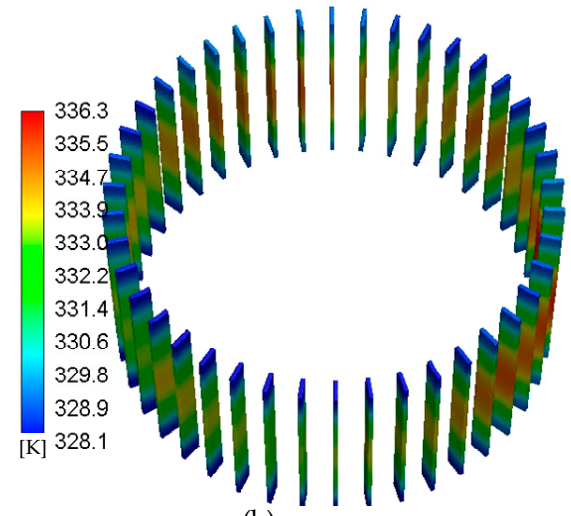

(b)

Figure 7. Winding temperature distribution. (a) Unidirectional coupling; (b) bidirectional coupling.

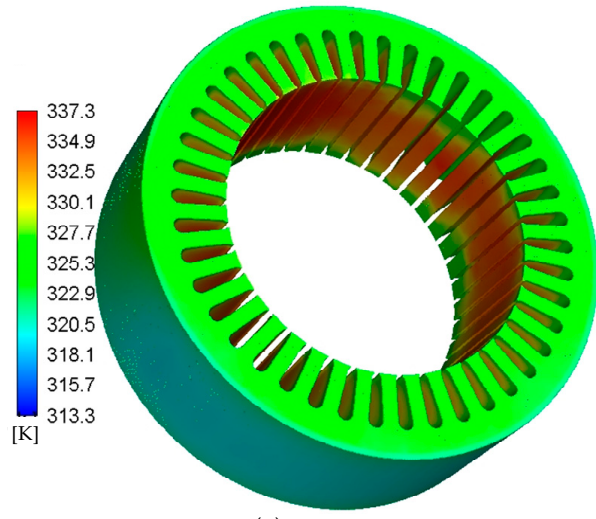

(a)

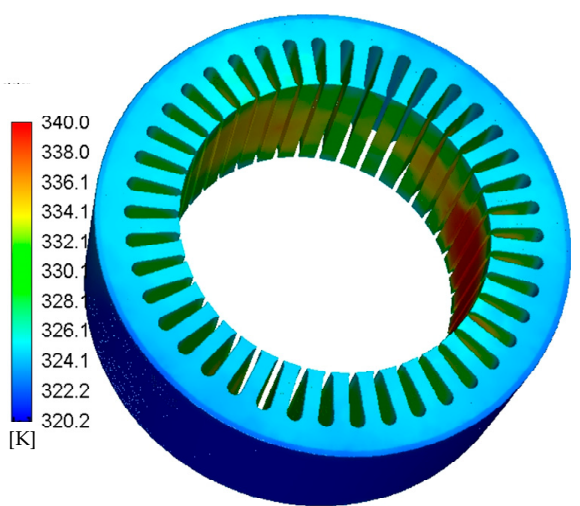

(b)

Figure 8. Stator temperature distribution. (a) Unidirectional coupling; (b) bidirectional coupling. 


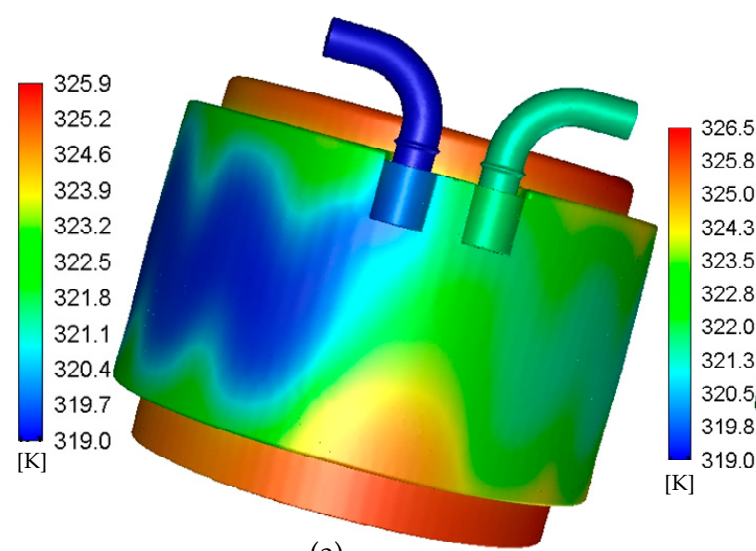

(a)

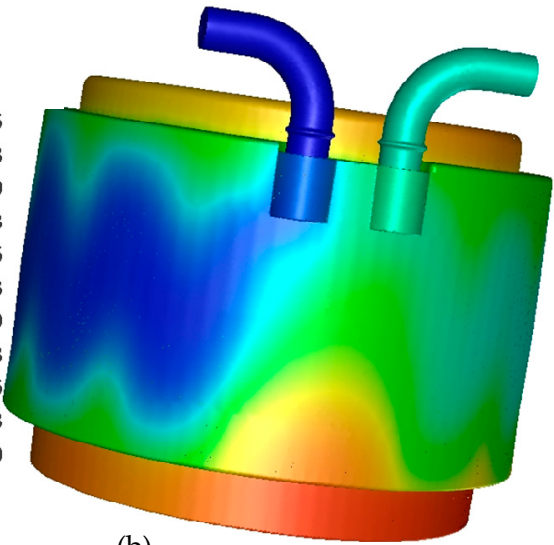

(b)

Figure 9. Shell temperature distribution. (a) Unidirectional coupling; (b) bidirectional coupling.

In Figure 7, due to the low thermal conductivity $(0.2 \mathrm{~W} / \mathrm{m}-\mathrm{k})$ of insulation filling glue around the winding, heat dissipation is difficult and the winding temperature rises greatly. The results show that the temperature of the bidirectional coupling model is about $1.6^{\circ} \mathrm{C}$ higher than that of the unidirectional coupling model. In both models, there is no filling around the end winding; thus, heat dissipation is easier, so the temperature in the middle of the winding is higher than that in the endings. The temperature toward both ends gradually decreases. This model simplifies the end winding; the temperature of the actual endings should be higher than that of the simulation result and will aggravate the temperature rise. The end winding is simplified not only because there is no filling, but also because it is too difficult to deal with in the process of finite element meshing. As the end is exposed to the air inside the motor, it can be simplified in terms of its heat release and heat dissipation rules, and it can be set separately when setting the heat release rate and other parameters.

In Figure 8, the temperature of the stator is higher in the axial center than that of both sides because of the better heat dissipation conditions of both ends. The results show that the temperature of the bidirectional coupling model is about $3{ }^{\circ} \mathrm{C}$ higher than that of the unidirectional coupling model.

In Figure 9, at the same inlet temperature and flow rate, the coolant temperature also increases. The results show that the temperature of the bidirectional coupling model is about $0.6{ }^{\circ} \mathrm{C}$ higher than that of the unidirectional coupling model. Due to design reasons, some locations in the water jacket are blind areas for water flow, so the temperature in these areas is high. The local temperature can be reduced by improving the structure of water jacket.

The simulation and test conditions are the rated conditions of the motor. Under this condition, the motor has higher efficiency and less loss, so the temperature rise is not obvious. However, in the process of model setting, all the simulation conditions are the same, only the temperature feedback module is turned on and the temperature difference appears. This shows that there are differences between two-way iteration and one-way iteration. Some limit conditions will be studied in the future.

The average temperatures of the 12 parts of both models are shown in Figure 10. The corresponding relationships between each serial number and part are as follows: 1 -water jacket, 2-shell, 3-air_s, 4-air_r, 5-shaft, 6-stator, 7-rotor_mass, 8-magnet, 9-rotor, 10-epoxy, 11-winding, and 12-glue.

In Figure 10, the temperature of bidirectional coupling is higher than that of unidirectional coupling. Due to poor thermal conductivity and the dual role of copper loss and iron loss, the temperature of glue is higher than that of the other parts. 


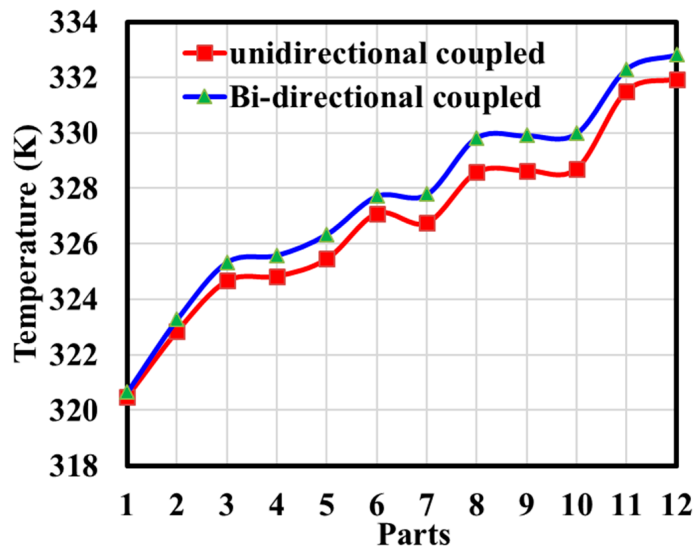

Figure 10. Temperature of different parts.

\subsection{Effect of Temperature Field on Electromagnetic Parameters}

Of both models established above, only the bidirectional coupling model can simulate the interaction of electromagnetic and thermal fields. The electromagnetic loss directly affects the distribution of the temperature of the motor. Meanwhile, when the temperature changes, besides the winding resistance changes, its self-inductance and mutual inductance also change, as shown in Figure 11. Similar conclusions can be referred to [33] to simulate the change in inductance with temperature in the actual working process. The flux amplitude of the windings decreases with the temperature, as shown in Figure 12.

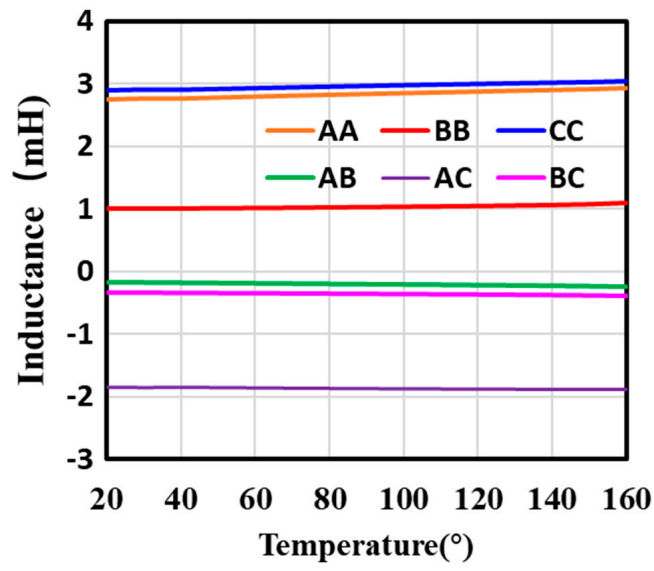

Figure 11. Inductance change of the windings.

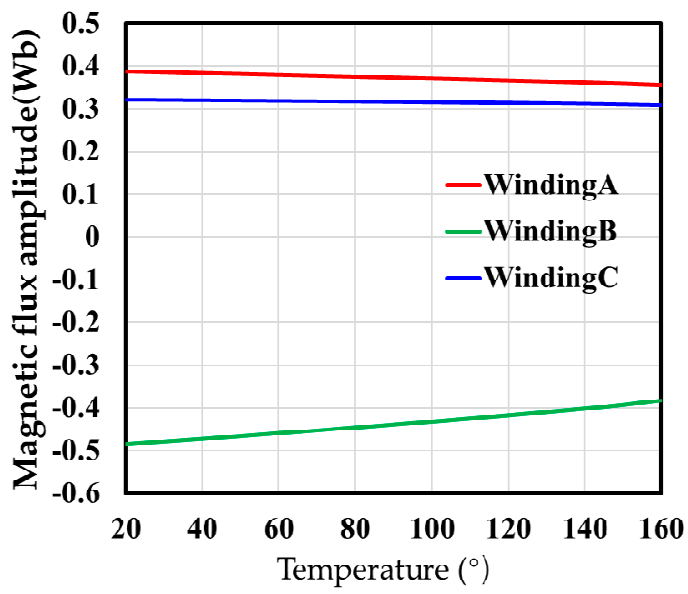

Figure 12. Magnetic flux change of the windings. 
In Figure 11, the self-inductance and mutual inductance of the windings change with the temperature. It can be seen from Figure 12 that the flux linkage in Winding A and Winding $C$ is positive, and the size is similar. The flux linkage in Winding $B$ is negative. The currents of Winding A, Winding B, and Winding C are 124.9 A, -211.8 A, and 86.9 A at $20^{\circ}$, respectively. In view of the same operating point, the other temperature points are similar. According to the inductance calculation formula, it can be inferred that the inductance curve in Figure 11 is reasonable. In Figures 11 and 12, as the temperature rises, the amplitude of the winding inductance increases, while the amplitude of the air-gap flux produced by windings decreases. The changes in coil self-inductance and mutual inductance are shown in Table 3.

Table 3. Ratio of the inductance change of the windings.

\begin{tabular}{llll}
\hline Windings & Ratio (\%) & Windings & Ratio (\%) \\
\hline AA & 6.28 & AB & 29.1 \\
BB & 9.35 & AC & 2.50 \\
CC & 5.10 & BC & 14.9 \\
\hline
\end{tabular}

The change rates of the induced flux density of the windings are $8.47 \%$ (Winding $\mathrm{A}$ ), $21.06 \%$ (Winding B), and 3.93\% (Winding C). The reduction in air gap flux will directly affect the output capacity of the motor. In this study, the speed of the motor remains. In order to maintain the output power of the motor, the magnetic flux density can only be increased. According to the motor performance calculation formula, in the case of a certain speed, the magnetic induction intensity B increases, and the output power of the motor increases. In the actual operation process, the magnetic induction intensity of the motor decreases because of the temperature rise. If the power required by the motor is to be maintained, the magnetic induction intensity must be increased. In both models, only the bidirectional coupling model will feed the temperature back into the electromagnetic model. The electromagnetic analysis results of unidirectional-coupled and bidirectionalcoupled models were compared, as shown in Figure 13. The maximum magnetic density increases from $2.8 \mathrm{~T}$ in the unidirectional-coupled model to $3.01 \mathrm{~T}$ in the bidirectionalcoupled model. In the bidirectional coupling model, considering the effect of temperature on electromagnetic performance, the electromagnetic iron loss and the copper loss (known as ohmic loss in the software) increase, which can also be seen from the comparison in Figures 14 and 15.

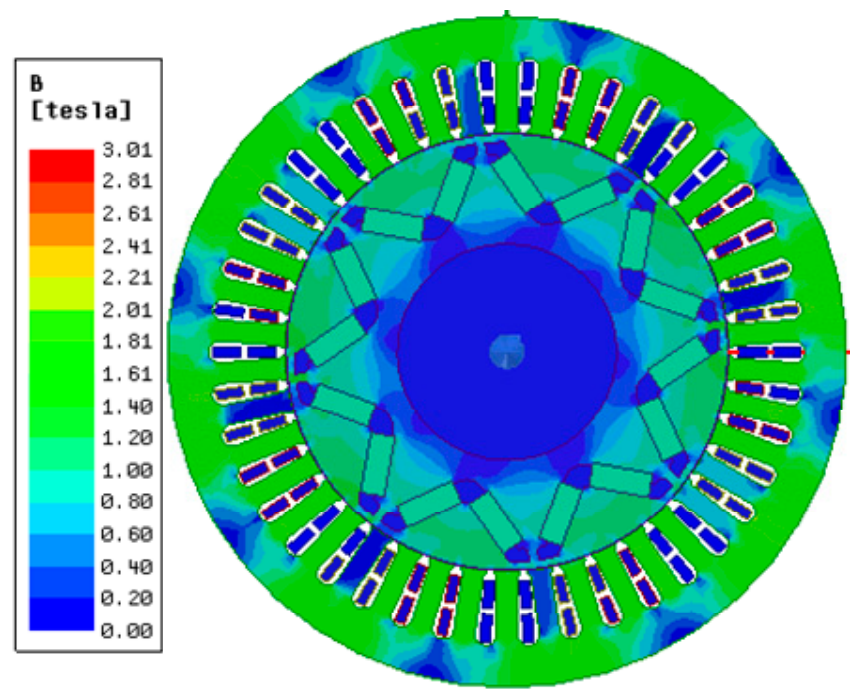

(a)

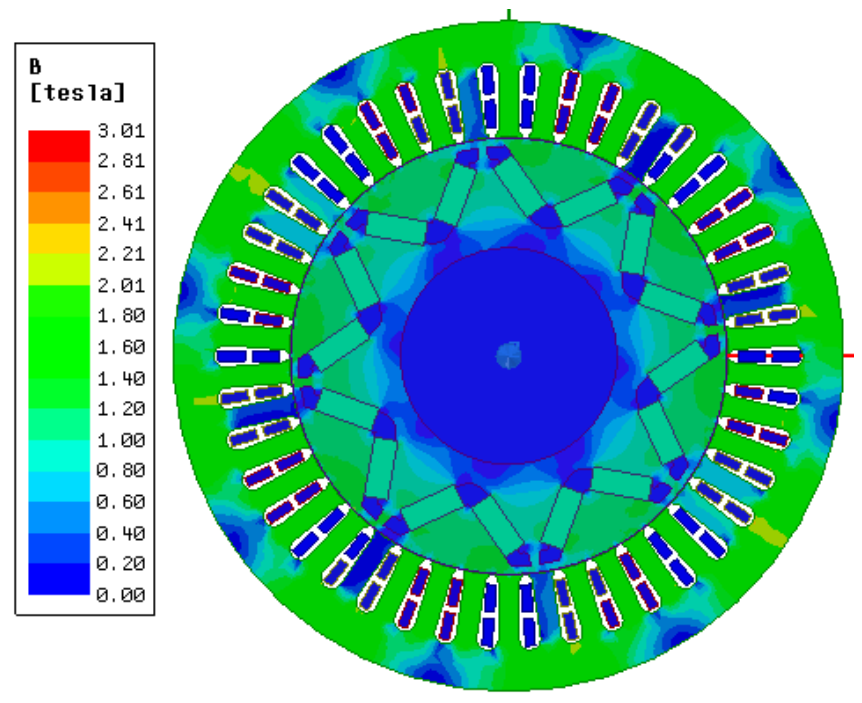

(b)

Figure 13. Magnetic flux density distribution. (a) Unidirectional coupling; (b) bidirectional coupling. 


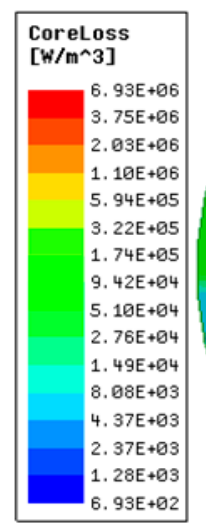

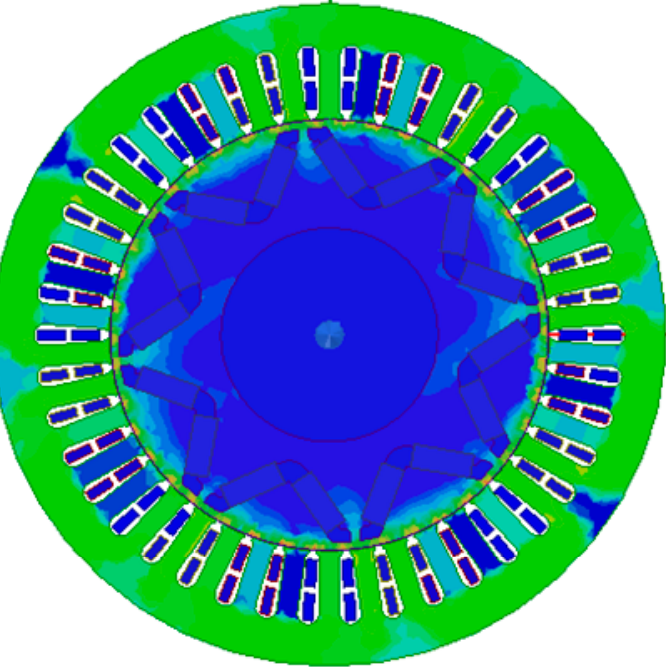

(a)

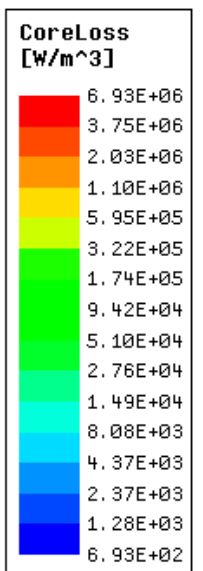

6. $93 \mathrm{E}+\square 2$

Figure 14. Iron loss. (a) Unidirectional coupling; (b) bidirectional coupling.

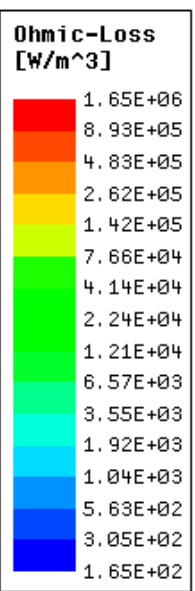

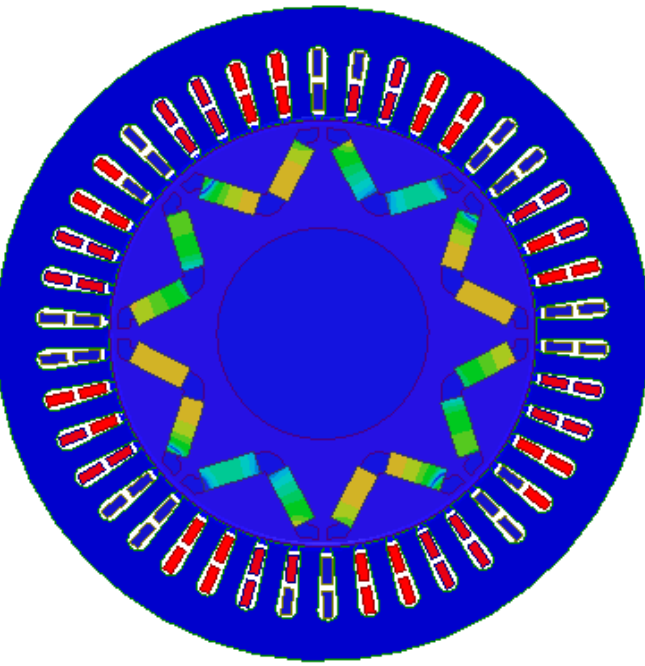

(a)

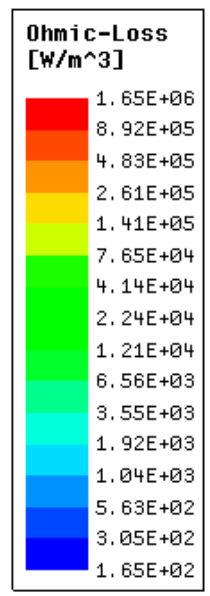

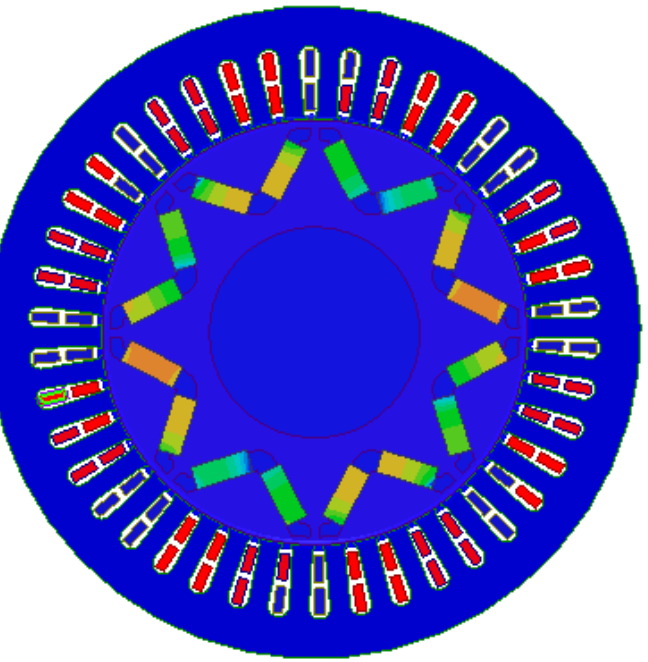

(b)

Figure 15. Ohmic-loss. (a) Unidirectional coupling; (b) bidirectional coupling.

In order to compare the influence of temperature change on the electromagnetic field more intuitively, the stator test temperature of $53^{\circ}$ was taken as the benchmark. The magnetic flux density of the air gap magnetic field at $20^{\circ}$ and $53^{\circ}$ were calculated as shown in Figure 16. Half of the total length of the circumference of the air gap line was normalized to 1 . The distance at other positions on the air gap line was the normalized distance.

As shown in Figure 16, when the temperature increases from $20^{\circ}$ to $53^{\circ}$, the magnetic flux density at the same air gap position decreases. Figure 15 shows the flux density around half the circumference of the center of the air gap. During the operation of the motor, the magnetic flux density in the air gap is generated by the permanent magnet and winding current. When the temperature increases, the air gap magnetic flux produced by the permanent magnet decreases. In order to keep the air gap magnetic flux density constant to maintain the motor output, a larger current is used to generate the magnetic flux density compared to at low temperature. Increasing the current input will increase the copper loss of the motor. Therefore, it is a good choice to reduce motor loss by controlling temperature. By controlling the temperature of the motor, it can also avoid damage to the 
winding insulation or permanent demagnetization of the permanent magnet, to ensure the power output of the motor.

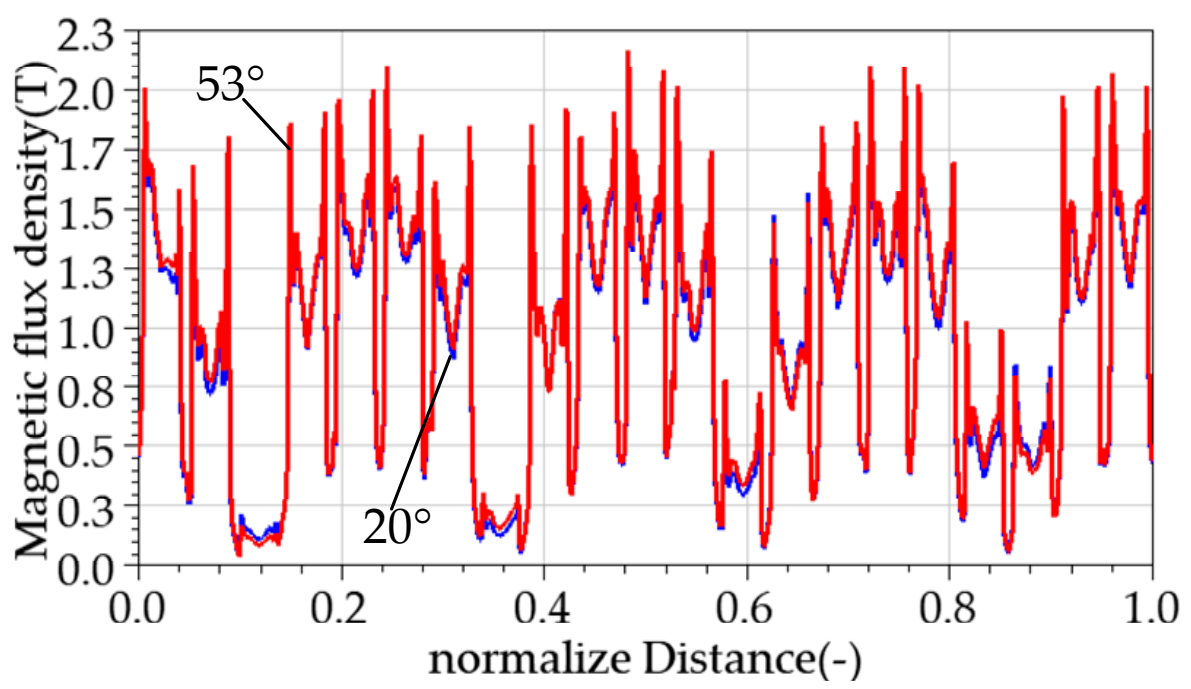

Figure 16. Air gap magnetic flux density at different temperatures.

\section{Experimental Verification}

In order to verify the results of FEM simulation, the measurement system was designed and set-up to test the temperature of the motor. Schematic diagrams of installation and test beds are shown in Figures 17 and 18, respectively.

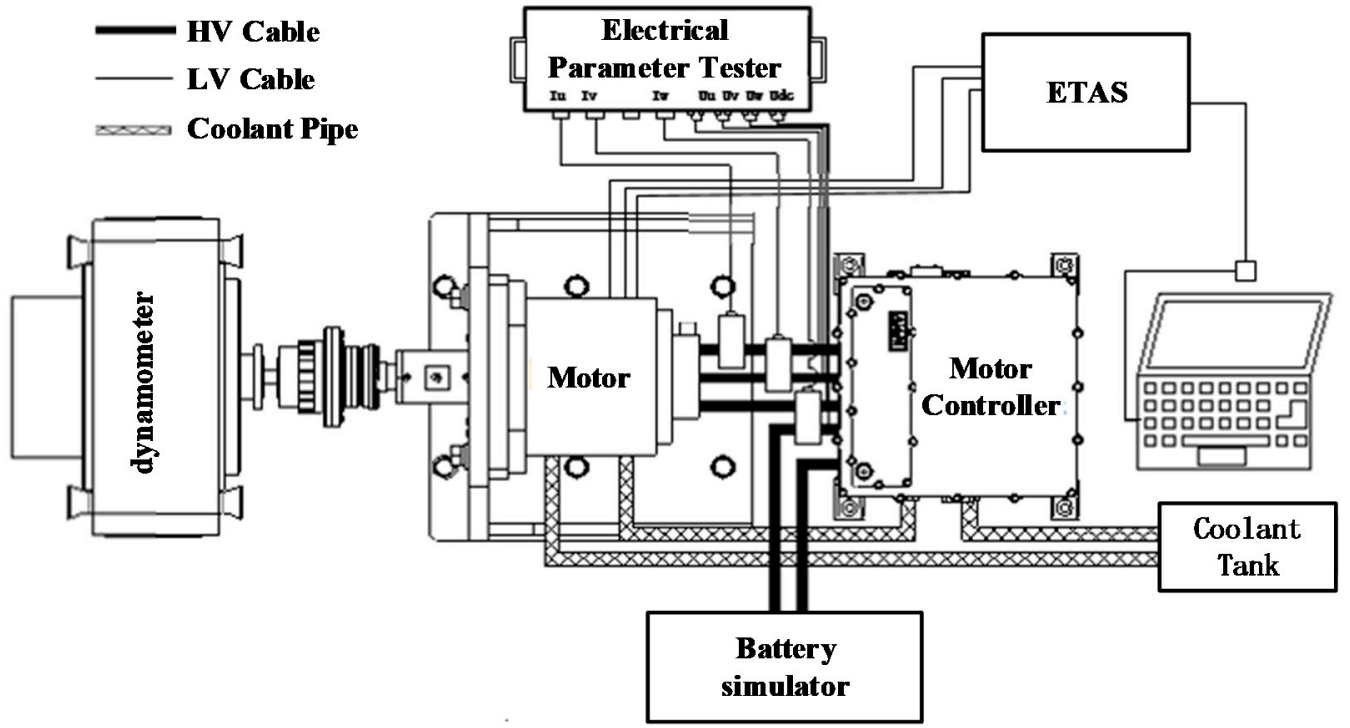

Figure 17. Schematic diagram of test bed. 


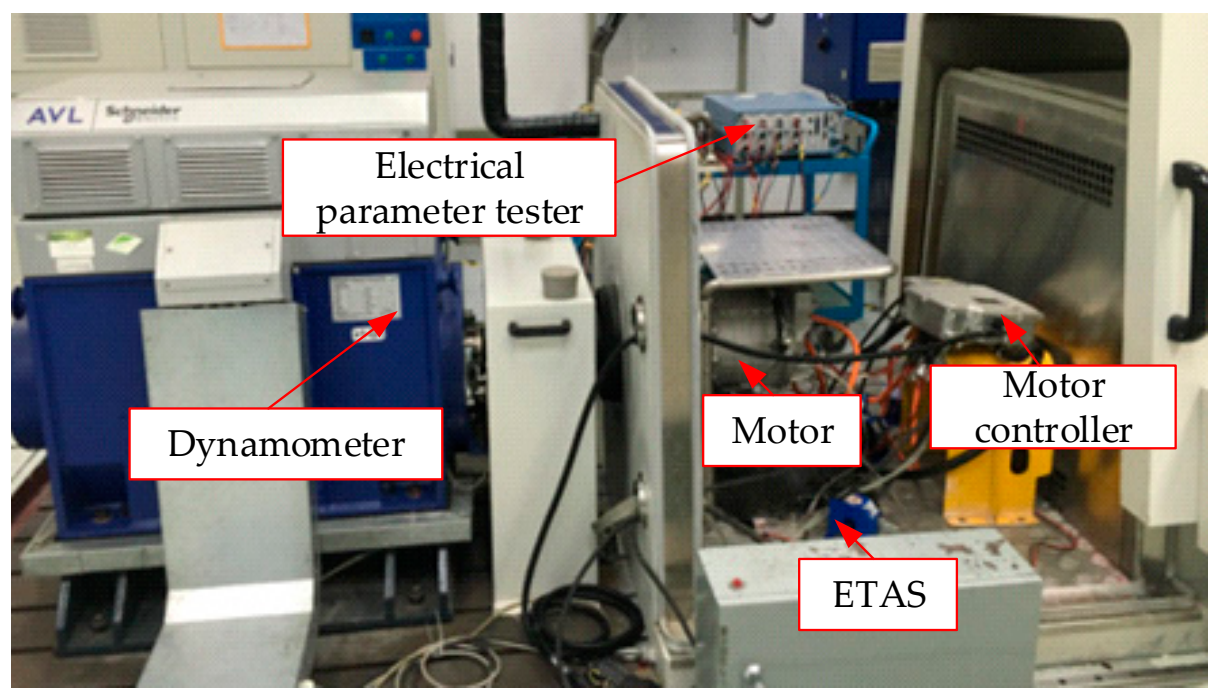

Figure 18. Experimental setup for temperature test.

Three temperature sensors were installed on the shell, stator, and glue. The results of temperature testing at the three parts by using the test instrument produced by environmental and technology application services (ETAS) and the supporting software integrated calibration and acquisition system (INCA) under the rated motor conditions are shown in Figure 19. ETAS is a wholly owned subsidiary of Bosch group. There are many main products, but here, the main application is its temperature test module. The preliminary work of the project only focuses on the rated working condition of the motor. Due to the needs of the project, the in-depth study of the motor will continue. The results of the simulation and test are listed in Table 4.

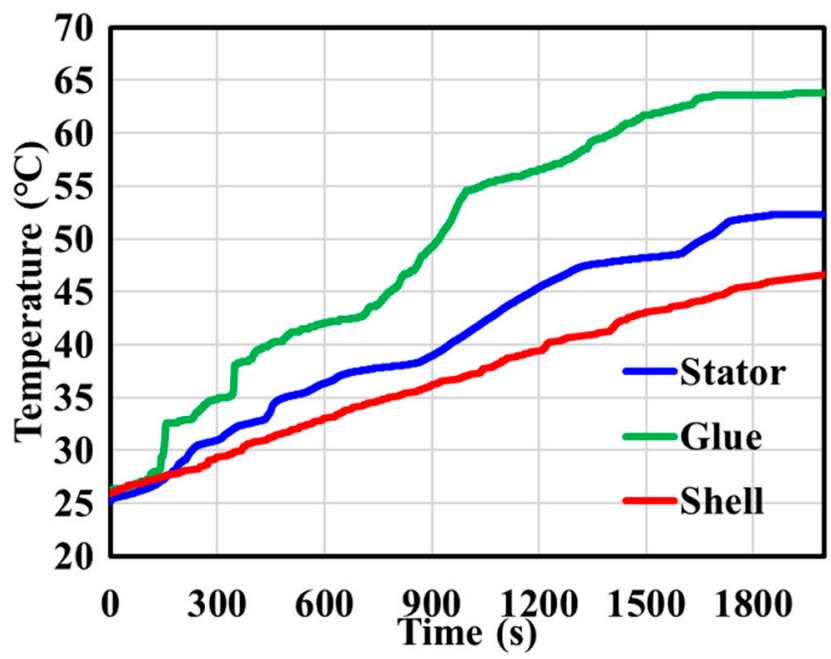

Figure 19. Test temperature.

Table 4. Comparison of simulated and measured temperatures.

\begin{tabular}{ccc}
\hline Part & Simulation Temperature $\left({ }^{\circ} \mathbf{C}\right)$ & Test Temperature $\left({ }^{\circ} \mathbf{C}\right)$ \\
\hline Shell & 50 & 46.4 \\
Glue & 59.5 & 63.4 \\
Stator & 54.4 & 53.4 \\
\hline
\end{tabular}

In Figure 19 and Table 4, after the temperature equilibrium (about $1800 \mathrm{~s}$ ), the test temperatures of the stator, glue, and shell are basically consistent with the temperature 
results of the bidirectional-coupled model. Therefore, the bidirectional-coupled model can be used to calculate the temperature distribution of the motor. The results can provide a reference for the motor design and reduce the number of tests.

\section{Conclusions}

In this paper, the unidirectional- and bidirectional-coupled models were established to simulate the temperature distribution of the motor, whereafter the motor was tested. The comparison between test results and analysis results showed that, as the motor is an electromagnetic-thermally coupled machine, the bidirectional-coupled model considers the interaction between the electromagnetic field and temperature field in the working motor, which is closer to the actual working process of the motor. The result of the bidirectional model was closer to the test result. The bidirectional model can be used to predict the temperature of the motor and serve as a reference for the design to reduce the test cost.

Author Contributions: Conceptualization, J.H.; data curation, M.J. and F.X.; formal analysis, M.J.; funding acquisition, J.H. and C.D.; investigation, M.J.; methodology, J.H. and Y.Y.; project administration, J.H. and F.X.; resources, C.D.; software, Y.Y.; supervision, J.H.; validation, M.J., Y.Y. and F.X.; visualization, M.J.; writing—original draft, M.J.; writing—review and editing, M.J. All authors have read and agreed to the published version of the manuscript.

Funding: This research was funded by the National Key R\&D Program of China under Grant No. 2018YFB0106100 and the Chongqing Technology Innovation and Application Development Project under Grant No. cstc2020jscx-dxwtBX0025.

Conflicts of Interest: The authors declare no conflict of interest.

\section{References}

1. Burkhardt, Y.; Spagnolo, A.; Lucas, P.; Zavesky, M.; Brockerhoff, P. Design and analysis of a highly integrated 9-phase drivetrain for EV applications. In Proceedings of the 2014 International Conference on Electrical Machines, Berlin, Germany, 2-5 September 2014; pp. $450-456$.

2. Liu, Q.; Hameyer, K. High-Performance Adaptive Torque Control for an IPMSM with Real-Time MTPA Operation. IEEE Trans. Energy Convers. 2017, 32, 571-581. [CrossRef]

3. Zhao, N.; Liu, W. Loss calculation and thermal analysis of surface-mounted pm motor and interior pm motor. IEEE Trans. Magn. 2015, 51, 1-4.

4. Li, G.; Ojeda, J.; Hoang, E.; Gabsi, M.; Lecrivain, M. Thermal-electromagnetic analysis for driving cycles of embedded fluxswitching permanent-magnet motors. IEEE Trans. Veh. Tech. 2012, 61, 140-151. [CrossRef]

5. Dong, J.; Huang, Y.; Jin, L.; Lin, H.; Yang, H. Thermal optimization of a high-speed permanent magnet motor. IEEE Trans. Magn. 2014, 50, 749-752. [CrossRef]

6. Huang, Z.; Fang, J.; Liu, X.; Han, B. Loss calculation and thermal analysis of rotors supported by active magnetic bearings for high-speed permanent-magnet electrical machines. IEEE Trans. Ind. Electron. 2016, 63, 2027-2035. [CrossRef]

7. Du, G.; Wang, H.; Liu, X.; Wang, Y. Multiphysics thermal analysis of a high speed permanent magnet brushless DC motor. In Proceedings of the 2011 International Conference on Electrical Machines and Systems, Beijing, China, 21-23 August 2011; pp. 1-5.

8. Luu, P.; Lee, J.; Lee, J.; Park, J. Electromagnetic and thermal analysis of a permanent magnet motor considering the effect of articulated robot link. Energies 2020, 13, 3239. [CrossRef]

9. Dong, J.; Huang, Y.; Jin, L.; Guo, B.; Lin, H.; Dong, J. Electromagnetic and thermal analysis of open-circuit air cooled high-speed permanent magnet machines with gramme ring windings. IEEE Trans. Magn. 2014, 50, 1-4. [CrossRef]

10. Joo, D.; Cho, J.; Woo, K.; Kim, B.; Kim, D. Electromagnetic field and thermal linked analysis of interior permanent-magnet synchronous motor for agricultural electric vehicle. IEEE Trans. Magn. 2011, 47, 4242-4245. [CrossRef]

11. Zhang, Y.; McLoone, S.; Cao, W.; Qiu, F.; Gerada, C. Power loss and thermal analysis of a mw high-speed permanent magnet synchronous machine. IEEE Trans. Energy Convers. 2017, 32, 1468-1478. [CrossRef]

12. Lee, J.; Kim, R.; Jung, H.; Yeo, H. Electromagnetic and thermal analyses of surface-mounted permanent magnet motor with flux-absorbing structure for enhancing overhang effect. IET Electr. Power Appl. 2020, 14, 2037-2043. [CrossRef]

13. Lu, Q.; Zhang, X.; Chen, Y.; Huang, X.; Ye, Y. Modeling and investigation of thermal characteristics of a water-cooled permanentmagnet linear motor. IEEE Trans. Ind. Appl. 2015, 51, 2086-2096. [CrossRef]

14. Nair, D.; Arkkio, A.; Haavisto, A. Power loss segregation in electrical machines through calorimetry and inverse thermal modelling. IET Electr. Power Appl. 2020, 14, 1127-1133. [CrossRef]

15. Son, H.; Lee, K. Distributed multipole models for design and control of PM actuators and sensors. IEEE/ASME Trans. Mechatronics. 2008, 13, 228-238. [CrossRef] 
16. Zeng, L.; Xing, D. Analysis of magnetic field and oil film bearing characteristics of a novel hybrid drive multi-DOF permanent magnet motor. In Proceedings of the 11th IEEE Conference on Industrial Electronics and Applications, Hefei, China, 5-7 June 2016; pp. 239-244.

17. Pan, D.; Li, L.; Wang, M. Modeling and optimization of air-core monopole linear motor based on multiphysical fields. IEEE Trans. Ind. Electron. 2018, 65, 9814-9824. [CrossRef]

18. Du, G.; Xu, W.; Zhu, J.; Huang, N. Power loss and thermal analysis for high-power high-speed permanent magnet machines. IEEE Trans. Ind. Electron. 2020, 67, 2722-2733. [CrossRef]

19. Seo, M.; Ko, Y.; Lee, T.; Kim, Y.; Jung, S. Loss reduction optimization for heat capacity improvement in interior permanent magnet synchronous machine. IEEE Trans. Magn. 2018, 54, 1-5. [CrossRef]

20. Du, A.; Zhang, D.; Sun, M. Study on temperature field of oil cold permanent magnet synchronous motor in hybrid electric vehicle. Autom. Tech. 2019, 4, 34-39.

21. Wang, J. Temperature Field Analysis and Heat Dissipation Optimization of Permanent Magnet Synchronous Motor for Pure Electric Vehicle. Master's Thesis, Jilin University, Jilin, China, 2019.

22. Chen, Q.; Shao, H.; Huang, J.; Sun, H.; Xie, J. Analysis of temperature field and water cooling of high speed permanent magnet synchronous motor for Electric Drive. IEEE Access. 2019, 48, 81-85.

23. Li, Z.; Chen, Q.; Wang, Q. Analysis of multi-physics coupling field of multi-degree-of-freedom permanent magnet spherical motor. IEEE Trans. Magn. 2019, 55, 1-5. [CrossRef]

24. Zhang, G.; Chen, C.; Gu, X.; Wang, Z.; Li, X. An improved model predictive torque control for a two-level inverter fed interior permanent magnet synchronous motor. Electronics 2019, 8, 769. [CrossRef]

25. Baik, J.; Yun, S.; Kim, D.; Kwon, C.; Yoo, J. Remote-state pwm with minimum rms torque ripple and reduced common-mode voltage for three-phase vsi-fed blac motor drives. Electronics 2020, 9, 586. [CrossRef]

26. Wu, S.; Huang, X.; Tian, C.; Zhang, P. Multi-physical field optimization analysis of high-speed permanent magnet synchronous motor based on NSGA-II algorithm. In Proceedings of the 2019 22nd International Conference on Electrical Machines and Systems (ICEMS), Harbin, China, 11-14 August 2019; pp. 1-6.

27. Chen, S.; Zhang, Q.; He, B.; Hui, D. Thermal analysis of high density permanent magnet synchronous motor based on multi physical domain coupling simulation. J Electr. Eng. Technol. 2017, 12, 91-99. [CrossRef]

28. Huang, X.; Liu, J.; Zhang, C.; Li, L. Calculation and experimental study on temperature rise of a high overload tubular permanent magnet linear motor. IEEE Trans. Plasma Sci. 2013, 41, 1182-1187. [CrossRef]

29. Bertotti, G. General Properties of power losses in soft ferromagnetic material. IEEE Trans. Magn. 1988, 24, 621-630. [CrossRef]

30. Bertotti, G. Hysteresis in Magnetism, 1st ed.; Academic Press: Cambridge, MA, USA, 1998; pp. 11-21.

31. Wei, Y.; Meng, D.; Wen, J. Aerodynamics and Heat Transfer in Motor, 1st ed.; China Machine Press: Beijing, China, $1998 ;$ pp. 76-77.

32. Tang, R. Modern Permanent Magnet Machines Theory and Design, 2nd ed.; China Machine Press: Beijing, China, $2017 ;$ pp. 18-19.

33. Zeng, X.; Wei, H.; Wang, X. Parameter Identification Method of Permanent Magnet Synchronous Motor Considering Temperature Influence. J. South China Univ. Tech. (Nat. Sci. Ed.) 2018, 46, 64-71. 